Copyright (C) 2015 by Academic Publishing House Researcher

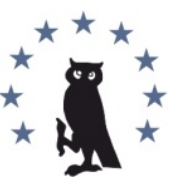

Published in the Russian Federation

European Researcher

Has been issued since 2010.

ISSN 2219-8229

E-ISSN 2224-0136

Vol. 98, Is. 9, pp. 590-596, 2015

DOI: $10.13187 /$ er.2015.98.590

www.erjournal.ru

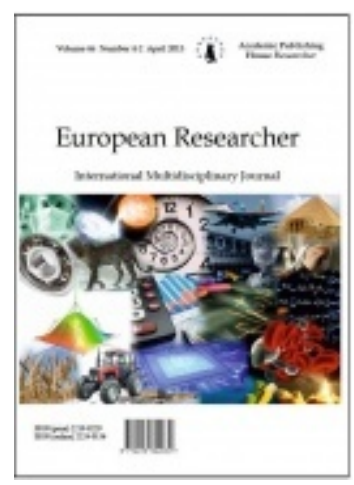

UDC 338.46.371

\title{
The Improving of Financial Relations in Higher Education Sphere in New Economic Terms
}

\author{
E.M. Filimontseva
}

South Russian institute of management - branch of the Russian academy of national economy and public service at the President of the Russian Federation, Russian Federation

Rostov-on-Don, street Pushkin, building 70; postcode 344002

$\mathrm{PhD}$ (economic)

E-mail: rustle44@mail.ru

\section{Abstract}

Modernization and reforming in an education sphere is transformation, change and a reorganization to this area according to operating requirements. In this connection new financial methods and the levers adapting all education system to new conditions of innovative and technological development are used. The formed complex of financial actions promoting effective development of economic relations in an education sphere became one of perspective directions of modernization of financial relations in system of the higher vocational training: working out of normative per capita financing, and also differentiated specifications of budgetary financing of higher educational institutions depending on character of realised curriculums. For realization of the given directions creation of conditions for attraction of additional means in high schools, maintenance with regulatory legal acts which will protect interests of higher educational institutions is supposed, will give possibility to use the tax privileges which use will promote successful re-structuring of budgetary reform.

Keywords: Educational institutions, the higher vocational training, modernization of financial relations, the financial mechanism of system of the higher vocational training (WPO), financial methods, financial levers, budgetary assignments, educational services, financing is standard-podushevoe.

\section{Введение}

С 1991 года, когда перестало существовать советское государство, рыночные отношения возобладали во всех сферах деятельности. Образование, как важная сфера деятельности, стало относиться к обслуживанию населения.

Вступили в силу законы рынка, экономические термины - покупатель, потребитель, образовательные услуги. Таким образом, и образование стало оказывать образовательные услуги.

До 1990 года российская система образования была одной из лучших в мире, но вступление на новый путь развития, где определяющими стали экономические законы, резко снизило конкурентоспособность образовательной системы. Так, в частности, в системе высшего 
профессионального образования наблюдаются тенденции, связанные с ослаблением централизованного управления этой отраслью.

Прежде всего это связано с социально-экономическими условиями, с наступившим в стране кризисом. Из-за отсутствия достаточных финансовых средств не обеспечивается в полной мере реализации бесплатного образования в области высшего образования.

Тенденции к ослаблению централизованного государственного управления и расширению самостоятельности высших учебных заведений находят свое отражение в изменениях нормативной правовой базы в области образования. Так, в 1996 году был принят Федеральный закон от 22.08.1996 № 125-ФЗ «О высшем и послевузовском профессиональном образовании». В соответствии с ним высшим учебным учреждением разрешалось осуществление платного обучения в пределах государственных образовательных стандартов и программ граждан, принимаемых на обучение сверх установленных контрольных цифр приема. В 2004 году Федеральным законом от 22.08.2004 № 122-Ф3 «О внесении изменений в законодательные акты РФ» отменялись социально-значимые нормы, действие которых в течение нескольких лет, приостанавливалось из-за отсутствия средств на их реализацию выплаты на питание, проезд, коэффициенты к стипендиям и др. С 2006 года стал действовать Федеральный закон от 03.11.2006 № 174-Ф3 «Об автономных учреждениях», затем был утвержден ряд постановлений Правительства РФ, необходимых для реализации данного нормативного акта. Вступивший в силу в 2011 году Федеральный закон от 08.05.2010 № 83-Ф3 «О внесении изменений в отдельные законодательные акты Российской Федерации в связи с совершенствованием положения государственных учреждений» был направлен на повышение эффективности предоставления государственных и муниципальных услуг [1]. При этом подчеркивалось, что расходы бюджетных средств на их предоставление сохранятся в прежнем объеме. Это возможно путем создания условий и стимулов для сокращения внутренних издержек учебных заведений и привлечения ими внебюджетных источников финансирования, а также создания условий и стимулов для федеральных органов исполнительной власти для оптимизации подведомственной сети.

Финансовое обеспечение деятельности вузов с принятием Федерального закона РФ от 08.05.2010 № 83-Ф3 осуществляется только в соответствии с государственным заданием по выполнению работ и оказанию услуг, относящихся к их основным видам деятельности, которыми для учебных учреждений являются образовательные услуги.

Бюджетные ассигнования, направляемые в систему ВПО, не отвечают потребностям вузов. Не учитываются объемы и направления их использования, реальные затраты на обучение студентов и те объемы средств, которые для этого выделяются. Финансовое обеспечение высших учебных заведений сгруппировано строго по кодам экономической классификации, имеет целевое назначение. И, как правило, такое распределение бюджета в уже утвержденной смете не отвечает текущим потребностям вуза.

Внесение корректировок расходов по статьям экономической классификации весьма затруднено - необходимо внести обоснованные предложения главному распорядителю бюджетных средств, только он имеет право вносить изменение в смету вуза.

Кроме того, право на изменение бюджетных средств может быть получено лишь в IY квартале текущего года, и то, только на оставшуюся часть лимита - что не способствует успешной деятельности вуза. Для учебных учреждений высшего профессионального образования установлен запрет на изменение бюджетных ассигнований по таким статьям и подстатьям экономической классификации, как «Прочие выплаты» (подстатья 212), и «Пособия по социальной помощи населению» (подстатья 262), «Прочие расходы (статья 290) (Рис. 1). 


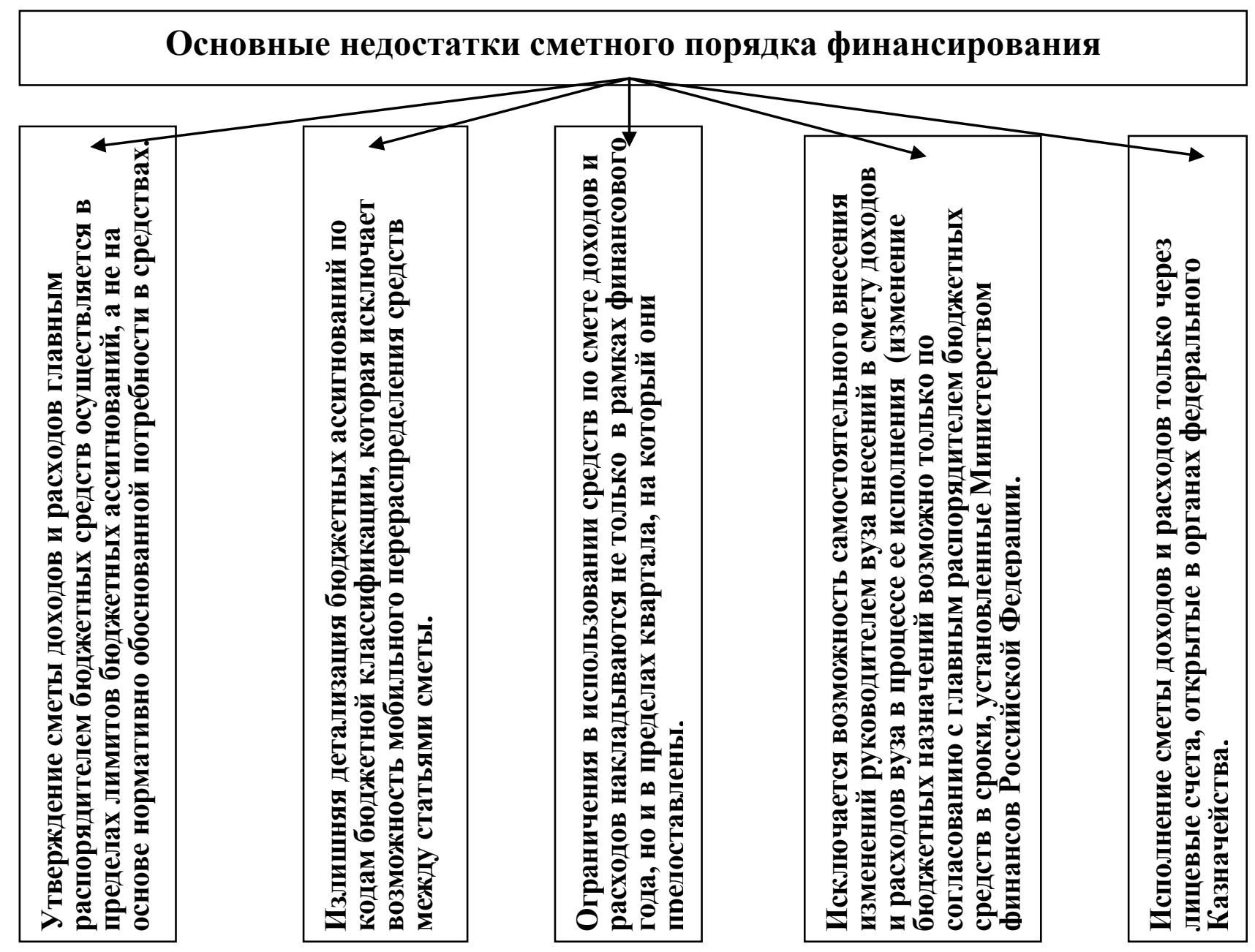

Puc. 1. Основные недостатки действовавшего порядка финансирования образовательных учреждений высшего профессионального образования

Таким образом, в рамках сметного финансирования налицо высокая степень зависимости вузов от принятия решений государственных органов относительно объемов и направлений использования бюджетных средств, выделяемых вузам, практически отсутствует корреляция между результатами обучения студентов и объемами бюджетного финансирования.

Недостаточное бюджетное финансирование системы ВПО повлекло за собой создавшееся критическое положение в области фундаментальной науки, ухудшение материально-технического обеспечения учебного процесса, прогрессирующий износ основных фондов высших учебных заведений. Снизился также престиж научно-технической работы. Все это привело к необходимости искать дополнительные внебюджетные средства для дальнейшего функционирования высших учебных заведений, наметилась тенденция коммерциализации высшего образования.

В этих условиях началась модернизация финансовых отношений в системе ВПО, конечная цель которой - обеспечение доступности качественного образования для всех слоев населения - как основы социальной мобильности и снижения социальноэкономической дифференциации в обществе.

Одним из направлений совершенствования финансово-экономических отношений в сфере образования стало использование финансового механизма, который можно представить как совокупность видов и форм организации финансовых отношений и методов 
использования денежных средств высшего учебного учреждения, в том числе государственных, в целях обеспечения реализации финансовой политики вуза для достижения его стратегических и тактических целей в соответствии с государственной политикой развития образования [5].

Это целый комплекс регулирования и использования финансовых средств вуза финансовые методы и финансовые рычаги, а также нормативно-правовое и информационно-методическое обеспечение. Все эти элементы взаимосвязаны между собой.

Среди финансовых методов можно выделить следующие: финансовый анализ, планирование и прогнозирование; финансовое обеспечение деятельности; финансовое регулирование - бюджетное и налоговое; бюджетирование, инвестирование, лизинг, финансовый контроль и учет; введение новых оплат труда; систему расчетов и др.

К финансовым рычагам относятся прежде всего ассигнования на содержание учреждений, а также субсидии, субвенции, бюджетные инвестиции, амортизация и арендная плата. Стипендии, процентная ставка, кредиты и займы; налоги, льготы и отсрочки; финансовые поощрения и санкции; взаимозачеты также занимают свое место среди финансовых рычагов [5].

К нормативно-правовому обеспечению финансового механизма системы ВПО относятся Конституция РФ, все нормативные акты Правительства РВ, а также нормативноправовые акты региональных и муниципальных органов власти и нормативные документы вузов.

Содержание финансового механизма также составляют бухгалтерский, управленческий и налоговый учет и отчетность, внутренняя финансовая документация, информация об источниках финансирования. Эти параметры представляют информационно-методическое обеспечение финансового механизма.

К сожалению, действующий финансовый механизм не отвечает основным направлениям и целям Концепции модернизации российского образования. Во-первых, в нем отсутствуют нормативы финансовых затрат, связанных с государственными услугами: нет четкого планирования бюджетных средств, методика планирования расходов увязывает лишь потребности вуза с возможностью бюджета. Во-вторых, вузы не могут самостоятельно распоряжаться бюджетными средствами по кодам экономической классификации при исполнении сметы доходов и расходов. В-третьих, учебные заведения также лишены самостоятельности в отношении собственных внебюджетных средств, так как они переводятся на счета органов федерального казначейства. К основных недостаткам механизма финансового обеспечения вузов относятся также отсутствие любых налоговых льгот при условии, если бюджетное учреждение занимается предпринимательской деятельностью.

Основным направлением государственной программы Российской Федерации «Развитие образования» на 2013-2020 годы, в соответствии с реализацией национального проекта «Образование», является формирование эффективных экономических отношений в этой области. Решить эту задачу можно лишь путем целого и взаимосвязанного между собой комплекса финансовых мероприятий. В их числе: разработка дифференцируемых нормативов бюджетного ассигнования для всей системы ВПО; нормативно-правовое обеспечение экономической самостоятельности высших учебных заведений; реализация принципа экономической автономии, включая расторжение своими внебюджетными средствами; создание условий для привлечения дополнительных средств, широкое использование льгот, в том числе налоговых [6].

Одной из новых форм финансового обеспечения предоставления государственных услуг, в свете реформирования финансовых отношений в сфере высшего образования, является базовый подушевой норматив. Его величина - это гарантированная минимальная стоимость бюджетной услуги, которая с учетом контрольных цифр приема обучающихся на очередной учебный год подлежит обязательному применению при формировании федерального бюджета. От обоснованности норматив зависит не только финансовое положение вуза, но и успех проводимых в этом направлении реформ.

Применение нормативного метода финансирования позволяет решить следующие задачи по финансовому обеспечению высшего учебного заведения: 
- осуществить расчет плановых объемов финансирования, приближенных к реальным затратам, связанным с оказанием образовательных услуг;

- уменьшить влияние субъективных факторов при распределении финансовых ресурсов (получение денежных средств становится гарантированным, не зависимым от административных решений);

- повысить самостоятельность вуза (финансовые средства поступают без разбивки по статьям экономической классификации, вуз сам определяет направление их использования).

К числу преимуществ нормативно-подушевого финансирования можно отнести следующие положительные факторы:

- его применение в деятельности высшего учебного учреждения - средство для выравнивая условий доступа молодежи к образованию, гарантированному Конституцией РФ и обеспеченному государственным финансированием (каждый обучающийся обеспечивается одинаковой суммой денежных средств из федерального бюджета);

- нормативно-подушевое финансирование является основой бюджетной политики, обязательной при формировании и использовании бюджета;

- нормативно-подушевое финансирование способствует оптимизации сети образовательных учреждений, развития элементов конкуренции между ними, а значит, более эффективному развитию образования.

В настоящее время осуществляется переход от финансирования образовательных учреждений к финансированию образовательных услуг, оказываемых потребителюобучающемуся.

В качестве недостатка нормативного финансирования, в котором объектом является образовательное учреждение, следует отметить наличие субъективного (административного) начала. Влияние этого фактора особенно усиливается из-за ограниченности финансовых средств. Негативной стороной нормативного финансирования является отрыв объема выделяемых государственных средств конкретно от обучающегося, так как в основном финансируется не учебный процесс, а в значительной степени содержание и эксплуатация материальных объектов системы образования: до 6о \% выделяемых финансовых ресурсов зависят от сложившейся материальной базы вузов.

И все же только в качестве единичного объекта финансирования - численности студентов есть возможность планировать расходы образовательным учреждением исходя из расчетного объема. Норматив подушевого финансирования обучения студентов является гарантированной нормой расходов бюджета на оплату обучения одного студента исходя из расходных обязательств государства в сфере ВПО. Норматив наглядно демонстрирует равный доступ любого гражданина, прошедшего конкурентный отбор, к получению высшего профессионального образования. Зная величину норматива, каждый из обучающихся будет знать, сколько денег государство обязано потратить на его обучение.

Вместе с тем ведение подушевого нормативного финансирования может иметь ряд негативных последствий, связанных с невозможностью учета особенностей сложившейся сети образовательных учреждений, их материальной базы, факторов, характеризующих нюансы реализации образовательного процесса в вузах одного вида и уровня образования.

В результате его применения возможно изменение финансового положения учебных заведений. Причем чем сильнее величина средних затрат на обучение одного студена в вузе будет отклоняться от норматива, тем больше это скажется на общем изменении финансового состояния всего учебного учреждения. Поэтому, чтобы избежать таких последствий, придется вести дополнительные поправочные коэффициенты или другие изменения, которые исказят саму систему нормативного финансирования.

Развитие конкуренции в системе ВПО может повлечь стихийную реструктуризацию сети образовательных учреждений, в том числе и их ликвидацию. Возможным следствием может стать сокращение доступа молодежи к качественному образованию. Стремление образовательных учреждений к сокращению затрат на учебный процесс повлечет за собой отказ от реализации высокозатратных программ, следовательно, к снижению качества обучения, т.е. в целом привести к негативным результатам.

Ожидания, связанные с развитием конкуренции между учебными заведениями, также могут не оправдаться - нормативно-подушевое финансирование, применяемое в вузах, 
станет препятствием для перехода обучающегося из одного учебного заведения в другое изза необходимости соответствующего переноса средств.

Отметим и тот факт, что теперь руководитель вуза, распределяя по статьям расходов выделенные бюджетные средства, сам будет решать, на какие нужды их направлять, например, на приобретение нового оборудования или для выплаты повышенной стипендии, успешно обучающимся студентам. В этом еще одна серьезная опасность на пути введения нормативного подушевого коэффициента.

Таким образом, назрела необходимость расчета научно-обоснованых нормативов, которые бы учитывали все вышеперечисленные факторы, препятствующие эффективному финансированию системы ВПО, соответствующими федеральными органами исполнительной власти.

Методы финансирования, которые зависят от реализуемых вузами программ, также до сих пор не разработаны. Однако за ними будущее успешное реформирование системы ВПО.

Отметим, что в настоящее время в Российской Федерации отсутствует адекватный механизм привлечения внебюджетных средств в сфере образования. Современное законодательство в области налогообложения сдерживает применение внебюджетных средств в системе ВПО. Хотя модернизация финансовых отношений в этой области предполагает возрастающую роль внебюджетных источников, финансирование в значительной мере высших учебных заведений за счет дополнительных платных образовательных услуг и предпринимательской деятельности.

На нынешнем этапе развития в условиях глобализации достижение эффективности образования в процессе модернизации финансовых отношений системы ВПО возможно лишь при взаимодействии государственных и рыночных рычагов. В связи с этим в процессе реформирования в сфере образования необходимо ввести изменения в действующие законодательные акты, чтобы облегчить адаптацию всей системы ВПО к условиям инновационного и технологического развития. Это необходимое условие для успешной деятельности высшей школы, в конечном итоге, для научного потенциала Российской Федерации.

\section{Примечания:}

1. Федеральный закон Российской Федерации от о8 мая 2010 года № 83-Ф3 “О внесении изменений в отдельные законодательные акты Российской Федерации в связи с совершенствованием правового положения государственных (муниципальных) учреждений” // Российская газета. 2010. 12 мая. № 5179 (100).

2. Ильинский И.М. Об экономической природе современного экономического образования [Электронный ресурс] / Сайт Игоря Михайловича Ильинского. Режим доступа: http:// www.ilinskiy.ru/ publications/ stat/ econprir.php

3. Шкель Т.М. Автономное плюс казенное // Российская газета. 2010. о2 февраля. № $5099(20)$. (100).

4. Кукол Е.А. Школа в трех вариантах // Российская газета. 2010. 12 мая. № 5179

5. Мальцева Г.И. Финансовый механизм и управленческий учет вуза в условиях бюджетных реформ. Владивосток: Изд-во ВГУЭС, 2006350 с.

6. Тараканов В.В. Финансовый механизм системы высшего профессионального образования: от трансформации к модернизации: монография. Волгоград: Изд-во ВолГУ, 2009.

7. Миргалеева И.В. Вопросы финансирования образовательных учреждений: Монография. М.: Бухгалтерский учет, 2009. 152 с.

\section{References:}

1. Federal'nyi zakon Rossiiskoi Federatsii ot o8 maya 2010 goda № 83-FZ "O vnesenii izmenenii v otdel'nye zakonodatel'nye akty Rossiiskoi Federatsii v svyazi s sovershenstvovaniem pravovogo polozheniya gosudarstvennykh (munitsipal'nykh) uchrezhdenii" // Rossiiskaya gazeta. 2010. 12 maya. № 5179 (100). 
2. Il'inskii I.M. Ob ekonomicheskoi prirode sovremennogo ekonomicheskogo obrazovaniya [Elektronnyi resurs] / Sait Igorya Mikhailovicha Il'inskogo. Rezhim dostupa: http:// www.ilinskiy.ru/ publications/ stat/ econprir.php (20).

3. Shkel' T.M. Avtonomnoe plyus kazennoe // Rossiiskaya gazeta. 2010. 02 fevralya. № 5099

4. Kukol E.A. Shkola v trekh variantakh // Rossiiskaya gazeta. 2010. 12 maya. № 5179 (100).

5. Mal'tseva G.I. Finansovyi mekhanizm i upravlencheskii uchet vuza v usloviyakh byudzhetnykh reform. Vladivostok: Izd-vo VGUES, 2006350 s.

6. Tarakanov V.V. Finansovyi mekhanizm sistemy vysshego professional'nogo obrazovaniya: ot transformatsii k modernizatsii: monografiya. Volgograd: Izd-vo VolGU, 2009.

7. Mirgaleeva I.V. Voprosy finansirovaniya obrazovatel'nykh uchrezhdenii: Monografiya. M.: Bukhgalterskii uchet, 2009. $152 \mathrm{~s}$.

УДК 338.46.371

\section{Совершенствование финансовых отношений в сфере высшего образования в новых экономических условиях}

Елена Михайловна Филимонцева

Южно-Российский институт управления - филиал Российской академии народного хозяйства и государственной службы при Президенте РФ, Российская Федерация 344002 Ростов-на-Дону, ул. Пушкинская, 70

Кандидат экономических наук

E-mail: rustle44@mail.ru

Аннотация. Модернизация и реформирование в сфере образования является преобразование, изменение и переустройство в этой области в соответствии с действующими требованиями. В связи с этим используются новые финансовые методы и рычаги, приспосабливающие всю систему образования к новым условиям инновационного и технологического развития. Одним из перспективных направлений модернизации финансовых отношений в системе высшего профессионального образования стал формируемый комплекс финансовых мероприятий, способствующий эффективному развитию экономических отношений в сфере образования: разработка нормативно подушевого финансирования, а также дифференцируемых нормативов бюджетного финансирования высших учебных заведений в зависимости от характера реализуемых учебных программ. Для осуществления данных направлений предполагается создание условий для привлечения дополнительных средств в вузы, обеспечение нормативноправовыми актами, которые будут защищать интересы высших учебных заведений, предоставят возможность пользоваться налоговыми льготами, использование которых будет способствовать успешной реструктуризации бюджетной реформы.

Ключевые слова: образовательные учреждения, высшее профессиональное образование (ВПО), модернизация финансовых отношений, финансовый механизм системы высшего профессионального образования, финансовые методы, финансовые рычаги, бюджетные ассигнования, образовательные услуги, нормативно-подушевое финансирование. 